\title{
SOLAR ENERGY STATUS AND POTENTIAL ASSESSMENT ACROSS KARACHI, PAKISTAN
}

\author{
Sabir Ali Kalhoro \\ Department of Electronics Engineering NED \\ University of Engineering and Technology \\ Karachi Pakistan. \\ E-mail: sabir13es66@gmail.com \\ Muhammad Shahid \\ Dawood University of Engineering \& \\ Technology, \\ Karachi, Pakistan. \\ E-mail: engr_shahid82@yahoo.com
}

\section{Rizwan Ali Lashari}

Department of Electronics Engineering NED

University of Engineering and Technology

Karachi Pakistan.

E-mail: rizwan.lashari71@yhoo.com
Muhammad Waleed

Indus University Karachi Pakistan.

E-mail: waleedyousuf12te91@gmail.com

Engr. Tufail Ahmed

Department of Electronics Engineering Mehran

University of Engineering and Technology Jamshoro, Pakistan.

E-mail: tufail.waseer@faculty.muet.edu.pk

Darakhshan Ara

Dawood University of Engineering \&

Technology, Karachi, Pakistan.

E-mail: ara.chemistry@yahoo.com

Recepción: 02/08/2019 Aceptación: 25/09/2019 Publicación: 06/11/2019

\section{Gitación sugerida:}

Ali Kalhoro, S., Shahid, M., Ali Lashari, R., Waleed, M., Ahmed, T. y Ara, D. (2019). Solar Energy Status and Potential Assessment across Karachi, Pakistan. 3C Tecnología. Glosas de innovación aplicadas a la pyme. Edición Especial, Noviembre 2019, 307-327. doi: http:/ / dx.doi.org/10.17993/3ctecno.2019.specialissue3.307-327

\section{Suggested citation:}

Ali Kalhoro, S., Shahid, M., Ali Lashari, R., Waleed, M., Ahmed, T. \& Ara, D. (2019). Solar Energy Status and Potential Assessment across Karachi, Pakistan. 3C Tecnología. Glosas de innovación aplicadas a la pyme. Speciaal Issue, November 2019, 307-327. doi: http:// dx.doi.org/10.17993/3ctecno.2019.specialissue3.307-327 


\section{ABSTRACT}

Renewable energy production in terms of solar irradiation comes is highly valuable for power generation. The World Bank Group (WB) investigated the quantity of intermittent renewable energy usage in regard to explore the existing solar power availability in Pakistan. The WB group put a strong effort to explore the renewable resources in the number of countries including Pakistan. The WB get the data available for all the observed countries. So the data obtained from WB sites located across Karachi. The solar data was studied by the WB group for the data sets in 20152017. In this paper, we have observed the solar irradiation trend and the fluctuation as for as the sunny day is concerned for the hourly, daily, monthly and yearly durations. The solar irradiations to be able to efficiently employ these renewable energy sources to meet the current and future power needs of Karachi of Pakistan. The Solar irradiation is available in the form of energy only need to explore it. We must use the python software for the solar irradiation trend observation for the Karachi.

\section{KEYWORDS}

Renewable energy, Solar energy, Solar irradiation, World bank observation. 


\section{INTRODUCTION}

Energy plays a biting role in socio-economic development by raising the level of the existing condition. The energy crisis is presently the foremost burning issue that is being faced by the whole world. Nowadays, Pakistan is facing an emerging energy crisis (Ashfaq \& Ianakiev, 2018; Kamran, 2018). Throughout the past decade, Pakistan's economy had shown positive growth and consequently, there was an increase in demand for energy however sadly no worthy steps are taken to put in new capability for generation of the desired energy sources. Currently, the demand exceeds the offer, by leading "load-shedding" that has become a standard development being round by the country (Sher, Murtaza, Addoweesh \& Chiaberge, 2015; Tahir \& Asim, 2018). The existing circumstances measure the results of lack of management. The faulty present energy management system, failure of forecast and future arrangement, put generating capability to transmit the load necessity. The grid stations and connected instrumentality unable to hold the load requirement and substantial distribution system of power provide the shortage (Best \& Burke, 2018; Wakeel, Chen \& Jahangir, 2016; Asif, 2009; K, 2009; Halacy, 1980; Ishaque, 2017 )

Pakistan incorporates a high potential for energy generation via a variety of native energy resource. Pakistan is the sixth richest nation due to coal manufacture. Additionally, the country is capable of manufacturing electricity by the atomic programs that were started by the Government in 1954. Despite the actual fact, Pakistan is gifted with the high potential of electricity generation from its available reserves. There are heavy reserves of fossil fuel principally within the southern and west part of Pakistan however because of the increase in usage, the country is facing a significant shortage of fossil fuel compromise. Pakistan has a good capability of power generation utilizing each commercially exploitable Hydel and geothermal resources. Although severe energy crisis, on the other hand, there's still hope that the country often strengthens the circumstance from the supplementary resources. The supplementary resources will satisfy the energy needs to adopt the varied short term and long run procedures. There is a variety of potential in Pakistan which is waiting for the green signal for the implementation to overcoming the increasing energy 
crisis (Ouria, 2019; Jung, Han \& Kim, 2019; Kabir et al., 2018; Prăvălie, Patriche \& Bandoc, 2019; Rauf, Wang, Yuan \& Tan, 2015; Zhang et al., 2019).

Fossil fuels remain the dominant energy supply within the international market. However, if consumption continues at its current rate, resources are going to be short among many decades attributable to their restricted provide. The fossil fuels based energy shows the emission of greenhouse gases and different other pollutants effect. To avoid the fast increase of greenhouse gases, the key lies within the improvement of energy potency on the buyer into renewable energy resources. Renewable energy is one of the foremost significant sources. This viable alternative source will exchange fossil fuels into vast pollution-free energy supply. Additionally, the environmental noticeable returns on the aspects will offer investment cherish by fossil fuels and might meet the stress of world energy consumption (Kamran, Fazal \& Mudassar, 2020; Ullah, Imran, Maqsood \& Butt, 2019; Lin \& Raza, 2019).

Over the past decade, Pakistan has been facing a shortage of between $3000 \mathrm{MW}$ and $6000 \mathrm{MW}$ within the supply and generation, resulting in many hours of loadshedding. The fundamental percentage of electricity generation is based on fossil fuels, resulting in price susceptibility. Where the geographical location and climate of the country tend to supply high alternative energy. The alternative resources signify the requirement for solar resource assessment for the look of alternative energy comes. The solar energy resource is highly supported by Pakistan due to the localization and topographical information carried out by the researchers. Numerous researchers have developed solar energy potential maps for the country's energy sector empowerment (Shah, Solangi \& Ikram, 2019; Wahab et al., 2019; Jung et al., 2019).

The solar irradiation is the most feasible source for the assessment of solar energy supply. The typical incident irradiance is needed to estimate the solar potential regionally. The solar irradiation works as freelance to upgrade the solar outcomes. Solar power produces the energy that gives the electricity and safe environment. The various hybrid, micro, nanogrid, urban block signifies the impact of solar electricity generation and potency. In addition, the economic profit in the reduction of utility values and environmental implication as $\mathrm{CO} 2$ emissions highlights the fundamental 
role of the solar system. So this alternative energy potential consequently fills the increasing demand-supply gap (Jung et al., 2019; Sadiqa, Gulagi \& Breyer, 2018;).

The solar system is capable to replace the fossil fuels at the location where high solar irradiation is available. The estimation of accessible solar power is the key to increasing energy generation as a result of sites with high available irradiation.

The solar resources give nice chances for energy production and use, thereby minimizing the loss by supply clean energy. Solar energy is one in every of the renewable energy resources with the best potential and will be the world's largest supplier of electricity by 2050 . The speedy increase within the use of solar energy in recent years highlights its nice development potential, and additional future energy source (Mirjat et al., 2017; Rafique \& Rehman, 2017; Dutta, 2019).

Solar energy has terribly obvious profit, particularly that the situation of the energy supply is usually constant because of the location of the energy use. The solar energy is applicable to build green energy capture through the "irradiation into electricity".

The basis of solar power is the sun irradiation supply which gives the limitless free energy all the time. Currently, new technologies are being used to get electricity by harvest solar energy. In Pakistan, the solar supply yield adequate power to exhibits the best potential to fulfill the growing gap of the demand and supply.

The solar energy is one in every of the most popular renewable resources that gives abundant energy in the replacement of minute investment. However, there is a lot of long gap in term of solar technology and solar power markets. The World Bank investigates the challenges for solar energy in Pakistan to identify the region-wise potential of solar energy. Pakistan opens the barriers to examine the solar power spectrum, policy problems, institutional roles and responsibilities to promote the solar power future (George et al., 2019; Badakhshan, Hajibandeh, Shafie-khan \& Catalão, 2019;).

The solar irradiation information measured by the Pakistan Meteorological Department (PMD) and the World Bank Group through the maps reported checking the solar availability within the region. The PMD compared the semi-permanent 
information from the World Radiation Data Centre (WRDG), and each information shows the valuable potential of solar energy.

The solar irradiation through the performance indicators of the World Bank provides insight as a location for establishing a solar system. The methodology and technical workflow as developed can support reliable and economical feasibleness studies, particularly within the early stage of discipline design.

Solar energy could be a key renewable supply for the decarbonization and therefore the future viable growth of social society. However, the success of the worldwide solar implementation depends on the in-depth information of irradiation distribution and intensity, which could upgrade the solar energy at the global perspective. This study primarily aims to analyze the solar supply and strength nationwide. The global horizontal irradiation $(\mathrm{GHI})$ and direct irradiation (DNI) are the key resources to gives the solar strength. The solar irradiation spatial information by the World Bank represents the reliable resolution for the solar power on the site of the selected region.

The World Bank group helps to choose the site that needed by many specialists to avoid subjective biases, usually wishing on rough estimations wherever the topography wasn't absolutely. Therefore, this study proposes a procedure methodology that estimates the potential of solar energy for prioritizing and choosing sites for power production from the PV system exploitation in public offered digital numerical maps (Reyes et al., 2019; Shahid, Kalhoro, Ara, Bano \& Perween, 2019; Kalhoro et al., 2019;).

\section{MODEL}

The Solar model is being responsible for the means of solar irradiation such as global irradiation, diffuse and direct normal solar irradiations established on the data of the World Bank assignment for Pakistan. The global horizontal irradiation (GHI) is the sum of diffuse and direct solar irradiation. It is best for the site chosen as the state in Eq.1. The diffuse horizontal irradiation (DHI) is dispersed by the sky as assumed by the World Bank in Eq.2. The direct normal irradiation (DNI) is the 
irradiation module of the solar that openly sticks the surface of the solar PV as presented in Eq.3. The zenith angle is defined as the angle vertical to the sun. The zenith angle is nighty degree with the elevation angle as given away in Eq.4. The elevation measured as the optimum selection for the site routine for the irradiation based solar power as described in Eq.5. The meteorological parameters are relative to the air temperature for solar irradiation power in the design system by the World Bank project. The meteorological parameters used to find the operating conditions and efficiency of the solar irradiation based project as specified in Eq.6. The Solar Atlas of the World Bank shows each parameter related to the generation of the solar power that evaluates the power generation from solar modules. The weather-related parameters verify the operation and performance of a solar energy project as defined in Eq.7. The air temperature determines the performance of the solar irradiation in the solar power system. Air temperature is used to determine the temperature of solar modules and uninterrupted impact on solar conversion efficiency in power damages. The World Bank gets the meteorological parameters for the solar project installation of the solar system. The solar electricity model algorithm incorporates the atlas which invariably provides an approximate for the electrical power that made at any site ruled by the interactive map as known in Eq. 8 to Eq. 11 .

$$
\begin{array}{cc}
G H I=D H I+D N I \cdot \cos (\theta) & \text { Eq. } 1 \\
\text { DHI }=\text { C. DNI } & \text { Eq. } 2 \\
\text { DNI }=\text { A. } \exp (-\mathrm{B} / \operatorname{Cos} \theta) & \text { Eq. } 3 \\
\zeta=90-\theta & \text { Eq. } 4 \\
\operatorname{Cos} \theta=\sin \delta \sin \varphi+\operatorname{Cos} \delta \operatorname{Cos} \varphi \cos \omega & \text { Eq. } 5 \\
\eta=\eta T r e f[1-\beta r e f(T c-\text { Tref })] & \text { Eq. } 6 \\
\eta_{p v g}=\eta_{r} \eta_{p c}\left[1-\beta\left(T_{c}-T_{r e f}\right)\right] & \text { Eq. } 7 \\
T_{c}=T_{a}+\left(\frac{N o c T-20}{800}\right) G_{t} & \text { Eq. } 8 \\
P_{p v}=\eta_{p v g} A_{p v g} & \text { Eq. } 9 \\
P_{M}=I_{S} V_{o c} & \text { Eq. } 10 \\
P_{\text {Array }}=N_{s} N_{s} P_{M} & \text { Eq. } 11
\end{array}
$$




\section{EXPERIMENTATION}

The World Bank has stabled a solar irradiation based project in order to evaluate the solar power in Pakistan. World Bank has set up solar staff through the number of countries including Pakistan. Pakistan has got so many number stations across the different coastal and non-coastal cities as a part of a global effort. The Karachi is the coastal city of the Pakistan and World Bank choose this city for the experimentation set up and site selection behind the data reported in this paper.

The meteorological station CSPS.MT.14.218 has been fitted on the rooftop of the Department of Industrial Management building of NED UET Karachi having the following direction $\left(24.9334^{\circ} \mathrm{N}, 67.1116^{\circ} \mathrm{E}\right)$ on April 22, 2015, as Figure 1.

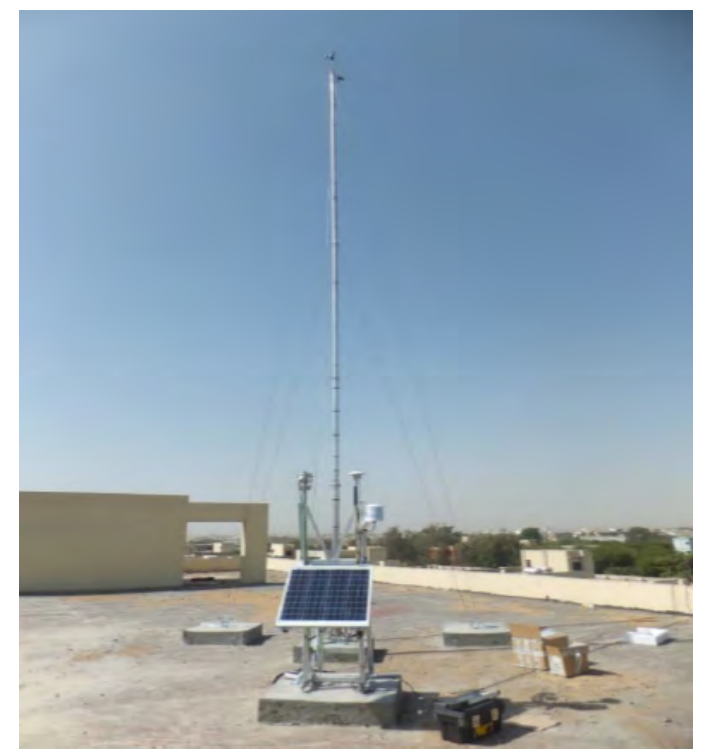

Figure 1. The Experimental setup for solar Station. Source: World Bank Site.

The World Bank set the solar station for the solar potential measurement in the whole scenario. The data of the different parameter is acquired in a period of every ten minutes. This data is continuously getting from 2015 to 2017 for solar power observation. 


\section{RESULTS}

The main results as regards the global horizontal irradiation (GHI) direct normal irradiation (DNI), direct horizontal irradiation (DHI), air temperature and the relative humidity are obtained by the active and passive solar systems. The solar irradiation result based on the conversion of the solar irradiation into the electric power in the hourly, daily, monthly and the yearly trend in the whole system as presented and discussed.

The Python indices the access information in a very essential Pandas measurement tools. Python information generally relates, and Pandas offers many supplementary detailed operations. As a result of Pandas was developed mostly in an exceedingly perspective, tools for monetary information. The related Pandas data packages are aware of the way to import monetary information from a variety of obtainable sources, together as "Yahoo" and "Google" Finance. In this way, Google's is used for the Program operation.

Pandas will make a date-time index which will be accustomed index information in an exceedingly series. The Pandas tools to repeat the demonstration from higher adaptably configured date and use codes to Process output. To make the formation of standard function for the sequences of convenient, Pandas offers some roles for this purpose.

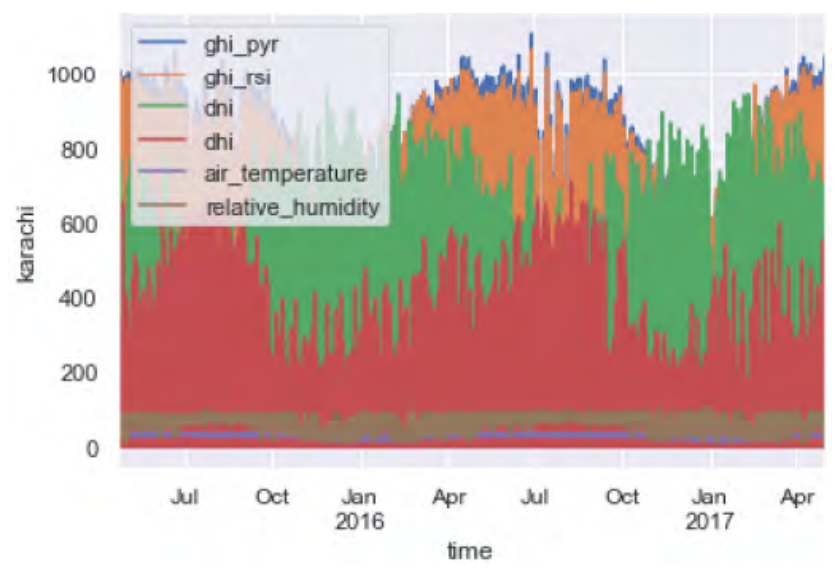

Figure 2. The weather parameter of solar irradiation for Karachi in each category of the solar data trendline is observed. 
The weather parameter of solar irradiation such as GHI, DNI, DHI, air temperature and relative humidity for Karachi in each category of the solar data trendline is observed. The python gain occurred by scheming the information. The software will gain a lot of comprehension by resampling the information to a rougher grid as shown in Figure 2. So we will resample it by the weekly, month and yearly trend.

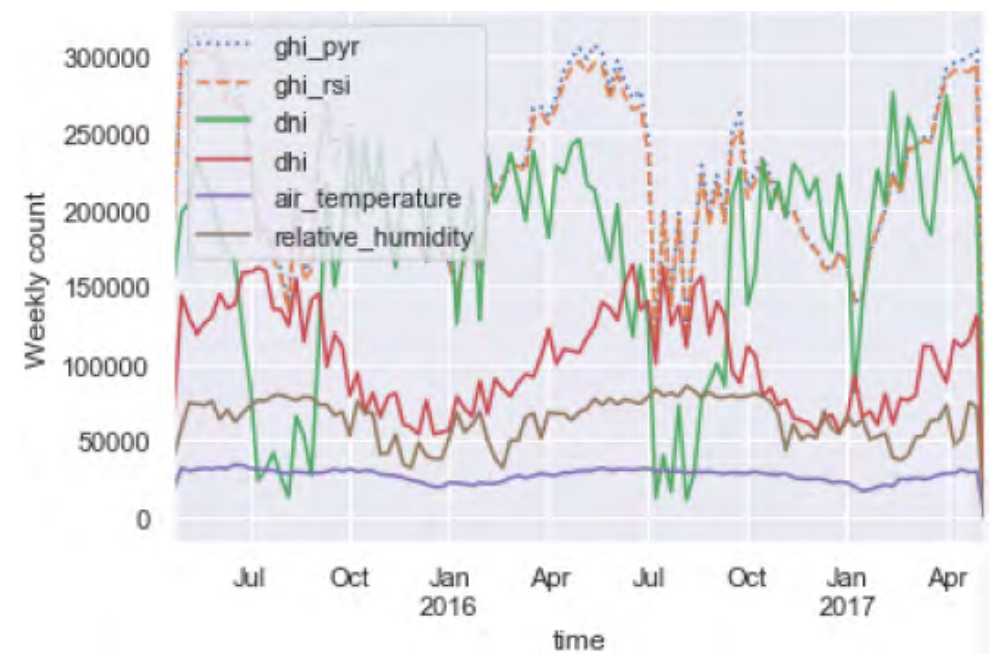

Figure 3. Solar Parameter for the Karachi are observed in a weekly count. The weekly count for the solar irradiation is examined for the period of Jan 2015 to April 2017.

The weekly count is done by the python in the very effective way now the python is ready for the monthly and the yearly trend as you may expect. The seasonal trend of the solar irradiation can be built to perform within the midsummer than within the winter, so among the selected seasonal fluctuation in a regression model. The all solar Parameter is again observed in a weekly count. The weekly count for the solar irradiation is examined for the period of 2015-2017. Wherever the python tends to explore further in a very minute period of time to gives the output as shown in Figure 3. 


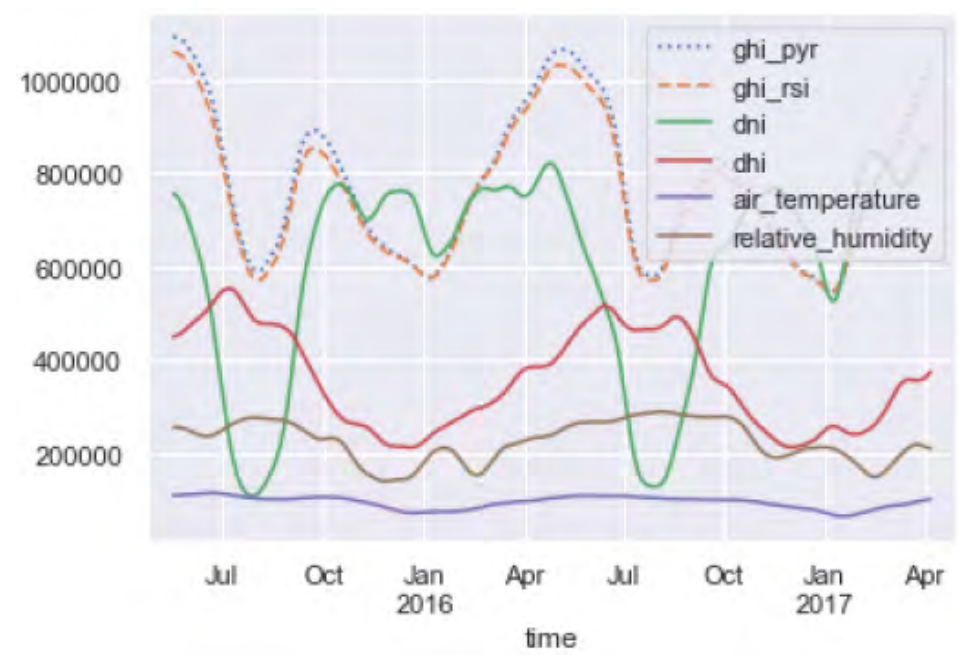

Figure 4. The periodic trend of solar parameter for the mean hourly count is experimented. The mean hourly count is investigated from Jan 2015 to April 2017.

The solar parameter trend for the mean hourly count is investigated. The mean hourly count has investigated the roughness in the results obtained by the arduous cutoff of the window in the yearly period is shown in Figure 4. The subsequent program requires a dimension of the window (selected fifty days) therefore the dimension of the Gaussian inside the frame.

The hourly trend of the bimodal distribution irradiation is given from the peaks around 00:00 to 24:00 within the morning and evening. This trend is often probably proof of a powerful part of crossing bridge for the solar irradiation in the system. The hourly trend of the model shows the limited variations between each hour of the observation. The irradiation generates the peaks power within the morning, and inadequately within the evening due to the irradiation strength. In this way, the python shows the trend of modification of the day of the week as consider Figure 5. 


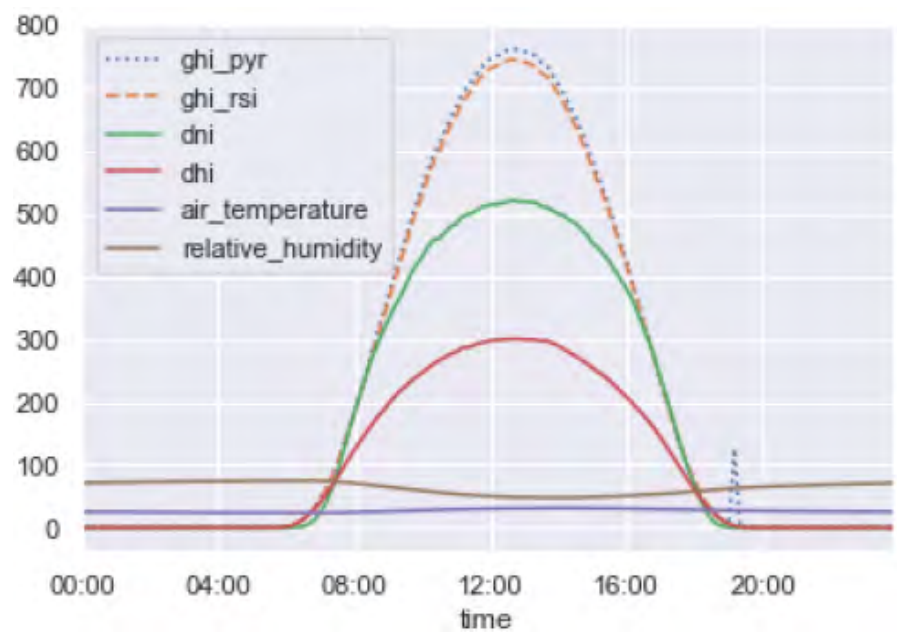

Figure 5. The hourly solar irradiation observation throughout the day. The different parameters are studied for the period of 25th April 2017.

While these information views measure the help to induce a plan of the overall irradiation trend within the information. Python gives a lot of fascinating structure for the solar irradiation based model in the selected way for the instance. The daily trend of solar irradiation is obtained for the time of day. The GHI and DNI show the trend of the day in the graph. The obtained victimization of the python is mentioned in Figure 6.

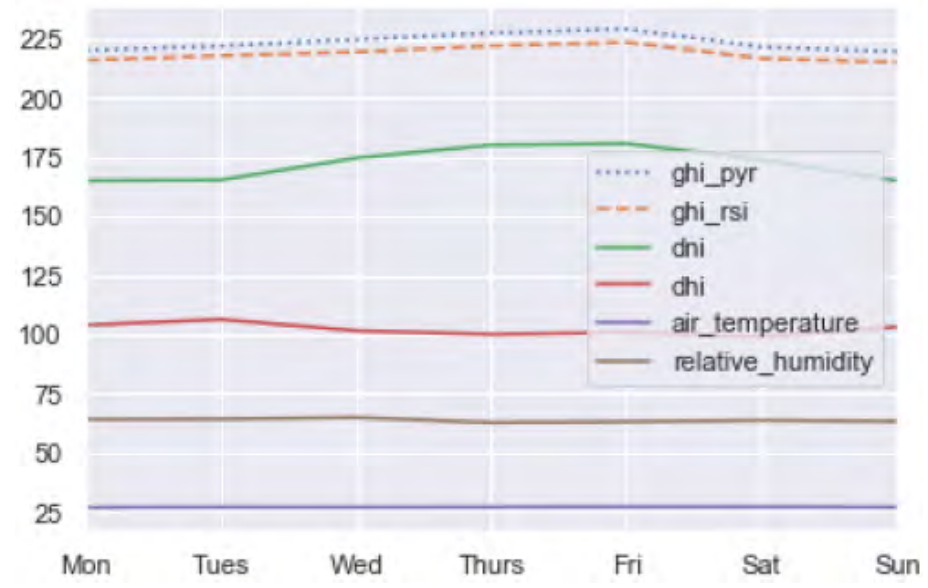

Figure 6. The daily observation of the solar irradiation with the consistent variations visible throughout the day. 
The weekday and the weekend trend of the irradiation are obtained to show the robust distinction between the output of the weekday and weekend totals. The day selection for the weekday and the weekend is Friday and Sunday. In the weekday and weekend, the hourly solar irradiation observation happens throughout the day. The different parameters are studied for the period of 25th April 2017. The irradiation for the appearance in the timely manner as presented in Figure 7.

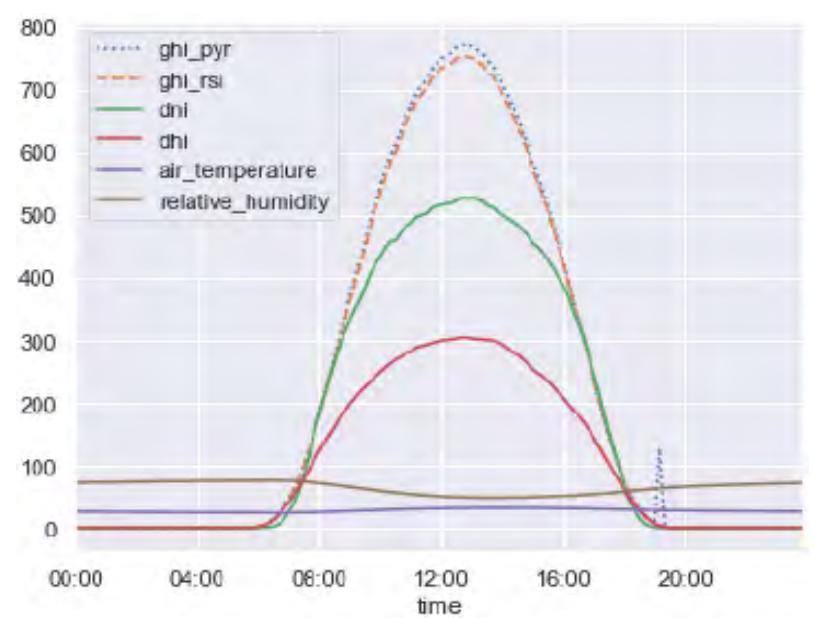

Figure 7. The hourly observation of the solar parameter that shows trend between the two days. The assessment shows the weekly basis Measurement for the Karachi.

The obtained result terribly interesting to see an irradiation modal commute pattern throughout the hourly, daily, monthly and yearly. The gained information gives the additional feature, that effect of weather parameter and different patterns which gives the best trend in the hourly, daily monthly and yearly result.

\section{ANALYSIS}

The World Bank aims to check the renewable energy potential across the different countries by fitted a project. The project will also be installed in Pakistan to evaluate the RE potential. The RE data is collected by the World Bank group in every 10 minutes from 2015-17. In this research, the World Bank data is being used to check solar availability in Pakistan. The available data is observed by daily, monthly and yearly trend to check solar irradiation for the solar power in Pakistan. The research 
points the consistent trend in weekly, daily, monthly and yearly data which gives the same trend for future use. Hence the research based on World Bank data proves the commendable solar accessibility that generates a huge amount of renewable energy in Pakistan. This data is observed by the Python software to check the solar irradiation obtainability as shown in Figure 2-7.

It is observed that the data for the daily trend from 22rd till 30th April show the highest trend in the irradiation also 23 April 2015, 23 April 2016 and 24 April of 2017 gives a similar trend. The days of 27 April 2015, 24 April 2016 and 23 April 2017 gives the lowest trend as refer Figure 2. The observed data have the irradiation availability in the April-May-June months from 2015 to 2017 and the lowest irradiation strength in the month of December-January 2015 to 2017 as shown in Figure 3-4.

The solar irradiation for the single day represents a high availability in the noon and the minimum from 8 am to 5 pm from 2015 to 2017 as presented in Figure 5 . The hourly observation of the solar parameter that shows the trend between the two days. The assessment shows the weekly basis measurement for the Karachi as in Figure 7. The irradiation is observed for a whole month of the year 2015-17 for the Karachi of Pakistan. The same resemblance of the result is observed all the time as solar radiations presence is highest in the months holding sunny days. Reliable with the summer, the solar irradiations are higher corresponding due to the solar angle. The whole analysis can be view by the solar atlas. In this atlas, the solar irradiation as GHI, DNI, and photovoltaic power potential prove the whole data analysis that is based on the World Bank calculation is shown in Figure 8. 

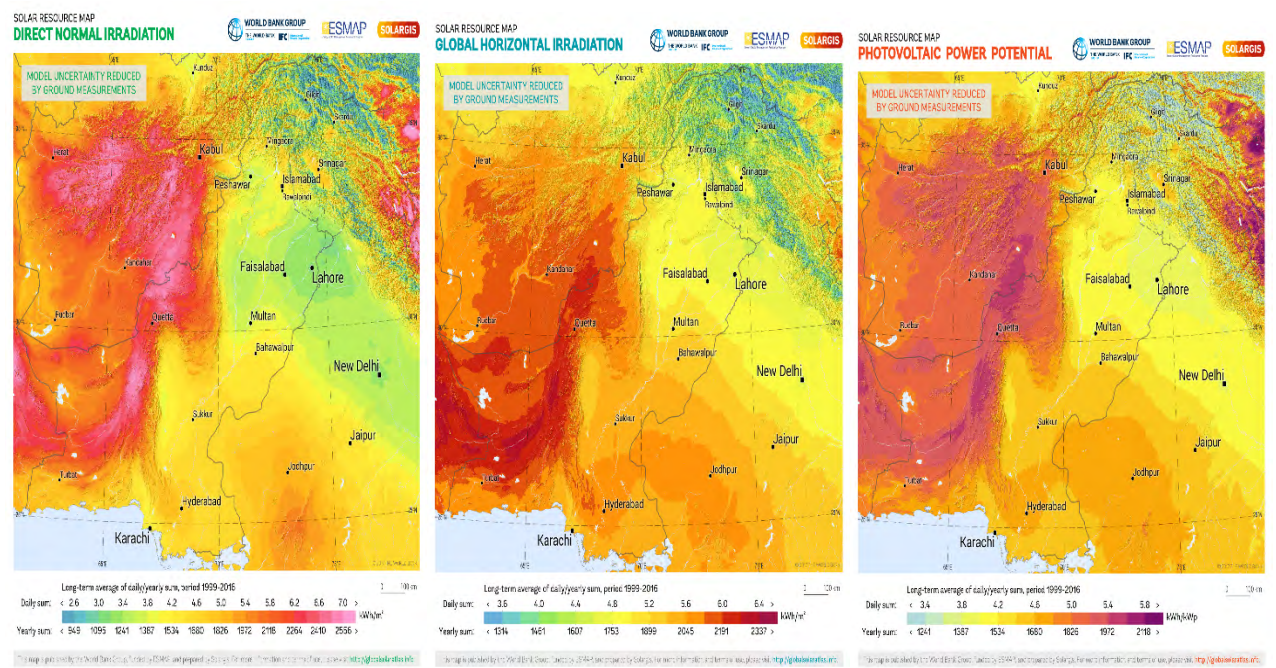

Figure 8. Global Horizontal irradiation, Direct Normal Irradiation, and photovoltaic power potential observation through Solar Atlas. Source: Solar Atlas World Bank Group.

\section{DISCUSSION}

The paper is based upon the solar energy potential offers by the World Bank in Pakistan. The World Bank group put a strong effort to explore the renewable resources in the number of countries including Pakistan. The World Bank group get the data available for all the observed countries. So the data obtained from World Bank sites located across Karachi. The solar data was studied by the World Bank Group for the data sets in 2015-2017. In this paper, we have observed the solar irradiation trend and the fluctuation as for as the sunny day is concerned for the hourly, daily, monthly and yearly durations. We must use the python software for the solar irradiation trend observation for the Karachi.

The Pandas, a package called in Python Software is employed for handling a large set of Python representing the dates, times, months, and timespans. The python was implemented as a framework of economic forming reasonably information. Time and day information arises in a very few senses, that are converse now for the irradiation based solar model. The reference explicit moments into the time intervals and periods of reference time between a specific starting and finish. The daily, 
monthly and yearly trend will be obtained by the typical reference of a special case in the time intervals in which uniform overlap between the time and value is obtained.

\section{CONCLUSION}

This paper is based upon the solar energy potential offers by the World Bank in Pakistan. The World Bank group put a strong effort to explore the renewable resources in the number of countries including Pakistan. The World Bank group get the data available for all the observed countries. So the data obtained from World Bank sites located across Karachi. The solar data was studied by the World Bank Group for the data sets in 2015-2017. In this paper, we have observed the solar irradiation trend and the fluctuation as for as the sunny day is concerned for the hourly, daily, monthly and yearly durations. We must use the python software for the solar irradiation trend observation for the Karachi.

\section{ACKNOWLEDGEMENTS}

Thanks World Bank for making the solar data available for Pakistan.

\section{REFERENCES}

Ashfaq, A., \& Ianakiev, A. (2018). Features of fully integrated renewable energy atlas for Pakistan; wind, solar and cooling. Renewable and Sustainable Energy Reviews, 97, 14-27. doi: https://doi.org/10.1016/j.rser.2018.08.011

Asif, M. (2009). Sustainable energy options for Pakistan. Renewable Sustainable Energy Review, 13, 903-909. doi: https://doi.org/10.1016/j.rser.2008.04.001

Badakhshan, S., Hajibandeh, N., Shafie-khan, M., \& Catalão, J.P.S. (2019). Impact of solar energy on the integrated operation of electricity-gas grids. Energy, 183, 844-853. doi: https://doi.org/10.1016/j.energy.2019.06.107 
Best, R., \& Burke, P. J. (2018). Adoption of solar and wind energy: The roles of carbon pricing and aggregate policy support. Energy Policy, 118, 404-417. doi: https://doi.org/10.1016/j.enpol.2018.03.050

Dutta, A. (2019). Impact of silver price uncertainty on solar energy firms. Journal of Cleaner Production, 225, 1044-105. doi: https://doi.org/10.1016/j. jclepro.2019.04.040

George, A., Boxiong, S., Arowo, M., Ndolo, P., Chebet, G., \& Shimmon, J. (2019). Review of solar energy development in Kenya: Opportunities and challenges. Renewable Energy Focus, 29, 123-140. doi: https://doi.org/10.1016/j. ref.2019.03.007

Halacy, J. D. S. (1980). Solar energy and the biosphere. Solar Energy Technology Handbook, Part A: Engineering Fundamentals, ed. W. C. and PN. Marcel. New York, 1-8.

Harijan, K., Uqaili, M.A., Memon, M., \& Mirza, U.K. (2009). Assessment of centralized grid connected wind power cost in coastal area of Pakistan. Renewable Energy, 34(2), 369-373. doi: https://doi.org/10.1016/j.renene.2008.05.001

Ishaque, H. (2017). Is it wise to compromise renewable energy future for the sake of expediency? An analysis of Pakistan's long-term electricity generation pathways. Energy Strategy Reviews, 17, 6-18. doi: https://doi.org/10.1016/j.esr.2017.05.002

Jung, J., Han, S.U., \& Kim, B. (2019). Digital numerical map-oriented estimation of solar energy potential for site selection of photovoltaic solar panels on national highway slopes. Applied Energy, 242, 57-68. doi: https://doi.org/10.1016/j. apenergy.2019.03.101

Kabir, E., Kumar, P., Kumar, S., Adelodun, A.A., \& Kim, K. H. (2018). Solar energy: Potential and future prospects. Renewable and Sustainable Energy Reviews, 82(1), 894-900. doi: https://doi.org/10.1016/j.rser.2017.09.094 
Kalhoro, S.A., Musvi, S.H.A., Ali, S., Rahoojo, S., \& Nawaz, A. (2019). An economical and relatively efficientimplementation of the Real-Time Solar Tracking System. 3C Tecnología, 68-99. doi: http://dx.doi.org/10.17993/3ctecno.2019. specialissue2.68-99

Kamran, M. (2018). Current status and future success of renewable energy in Pakistan. Renewable and Sustainable Energy Reviews, 82(1), 609-617. doi: https://doi. org/10.1016/j.rser.2017.09.049

Kamran, M., Fazal, M. R., \& Mudassar, M. (2020). Towards empowerment of the renewable energy sector in Pakistan for sustainable energy evolution: SWOT analysis. Renewable Energy, 146, 543-558. doi: https://doi.org/10.1016/j. renene.2019.06.165

Lin, B., \& Raza, M. Y. (2019). Analysis of energy related CO2 emissions in Pakistan. Journal of Cleaner Production, 219, 981-993. doi: https://doi.org/10.1016/j. jclepro.2019.02.112

Mirjat, N.H., Uqaili, M.A., Harijan, K., Valasai, G.D., Shaikh, F., \& Waris, M. (2017). A review of energy and power planning and policies of Pakistan. Renewable and Sustainable Energy Reviews, 79, 110-127. doi: https://doi. org/10.1016/j.rser.2017.05.040

Rafique, M.M., \& Rehman, S. (2017). National energy scenario of PakistanCurrent status, future alternatives, and institutional infrastructure: An overview. Renewable and Sustainable Energy Reviews, 69, 156-167. doi: https://doi. org/10.1016/j.rser.2016.11.057

Ouria, M. (2019). Solar energy potential according to climatic and geometrical parameters of cities and buildings: A case-study from Tabriz City- Iran. Urban Climate, 28, 100469. doi: https://doi.org/10.1016/j.uclim.2019.100469

Prăvălie, R., Patriche, G., \& Bandoc, G. (2019). Spatial assessment of solar energy potential at global scale. A geographical approach. Fournal of Cleaner Production, 209, 692-721. Doi: https://doi.org/10.1016/j.jclepro.2018.10.239 
Rauf, O., Wang, S., Yuan, P., \& Tan, J. (2015). An overview of energy status and development in Pakistan. Renewable and Sustainable Energy Reviews, 48, 892-931. doi: https://doi.org/10.1016/j.rser.2015.04.012

Reyes, A., Pailahueque, N., Henríquez-Vargas, L., Vásquez,J., \& Sepúlveda, F. (2019). Analysis of a multistage solar thermal energy accumulator. Renewable Energy, 136, 621-631. doi: https://doi.org/10.1016/j.renene.2018.12.103

Sadiqa, A., Gulagi, A., \& Breyer, C. (2018) Energy transition roadmap towards $100 \%$ renewable energy and role of storage technologies for Pakistan by 2050. Energy, 147, 518-533. doi: https://doi.org/10.1016/j.energy.2018.01.027

Shah, S. A. A., Solangi, Y. A., \& Ikram, M. (2019). Analysis of barriers to the adoption of cleaner energy technologies in Pakistan using Modified Delphi and Fuzzy Analytical Hierarchy Process. Journal of Cleaner Production, 235, 1037-1050. doi: https://doi.org/10.1016/j.jclepro.2019.07.020

Shahid, M., Kalhoro, S.A., Ara, D., Bano, N., \& Perween, R. (2019). Wind and solar energy Potentials around Southern Sindh \& Southern Baluchistan provinces, especially Karachi of Pakistan. 3C Tecnología, 116-141. doi: https:// doi.org/10.17993/3ctecno.2019.specialissue2.116-141

Sher, H. A., Murtaza, A. F., Addoweesh, K. E., \& Chiaberge, M. (2015). Pakistan's progress in solar PV based energy generation. Renewable and Sustainable Energy Reviewes, 47, 213-217. doi: https://doi.org/10.1016/j.rser.2015.03.017

Tahir, Z. R., \& Asim, M. (2018). Surface measured solar radiation data and solar energy resource assessment of Pakistan: A review. Renewable and Sustainable Energy Reviews, 81(2), 2839-2861. doi: https://doi.org/10.1016/j.rser.2017.06.090

Ullah, A., Imran, H., Maqsood, Z., \& Butt, N. Z. (2019). Investigation of optimal tilt angles and effects of soiling on PV energy production in Pakistan. Renewable Energy, 139, 830-843. doi: https://doi.org/10.1016/j.renene.2019.02.114

Wahab, A., Hassan, A., Arslan, M., Ali, H.M., Babar, H., \& Sajid, M. U. (2019) Solar energy systems-Potential of nanofluids. Fournal of Molecular Liquids, 289, 111049. doi: https://doi.org/10.1016/j.molliq.2019.111049 
Wakeel, M., Chen, B., \& Jahangir, S. (2016). Overview of Energy Portfolio in Pakistan. Energy Procedia, 88, 71-75. doi: https://doi.org/10.1016/j. egypro.2016.06.024

Zhang, J., Xu, L., Shabunko, V., Rong Tay, S.E., Sun, H., Yu Lau, S.S., \& Reindl, T. (2019). Impact of urban block typology on building solar potential and energy use efficiency in tropical high-density city. Applied Energy, 240, 513533. doi: https://doi.org/10.1016/j.apenergy.2019.02.033 
Edición Especial Special Issue Noviembre 2019

DOI: http://dx.doi.org/10.17993/3ctecno.2019.specialissue3.307-327 